\title{
A experiência educativa do Projeto "Conhecendo a diversidade das plantas vasculares da Floresta Amazônica"
}

\author{
Andréia Silva Flores
}

Instituto de Amparo à Ciência, Tecnologia e Inovação de Roraima (IACTI-RR), Herbário do Museu Integrado de Roraima (MIRR), Av. Brigadeiro Eduardo Gomes 1128, CEP 69330-640, Boa Vista, RR, Brasil.

Email: andreiasflores@gmail.com

Recebido em : 23 de maio de 2016. Aceito em: 21 de junho de 2016. Publicado PDF em: 30 de junho de 2016

\section{RESUMO}

\begin{abstract}
A experiência educativa do Projeto "Conhecendo a diversidade das plantas vasculares da Floresta Amazônica". A experiência educativa do Projeto "Conhecendo a diversidade das plantas vasculares da Floresta Amazônica". Este trabalho tem como objetivo o relato da experiência de uma atividade de divulgação científica sobre a diversidade da flora amazônica na Semana Nacional de Ciência e Tecnologia em um município no interior do estado de Roraima. Durante este evento foi realizado um minicurso sobre a diversidade de espécies vegetais presentes nas Florestas Amazônicas para licenciandos e professores do ensino fundamental. Algumas reflexões são feitas sobre a importância destas atividades para comunidades distantes dos centros de pesquisa no estado e como estas ações podem auxiliar ao estímulo a aprender sobre as plantas.
\end{abstract}

PALAVRAS CHAVE: Divulgação científica, botânica, ensino de ciências, Amazônia.

\section{ABSTRACT}

The educational experience from project "Knowing the vascular plant diversity of Amazon rainforest". This paper describes an experience of science communication activities about the Amazonian flora diversity during the Semana Nacional de Ciência e Tecnologia event in Roraima state. During this event was held a short course on the plant diversity in Amazon rain forest areas for undergraduate students and elementary school teachers. Some reflections concerning the importance of these activities to distant communities of research centers in Roraima state and how these actions can help to stimulate learning about the plants are presented.

KEY WORDS: Science communication, Botany, Science education, Amazonian rainforest taxonomy.

\section{INTRODUÇ̃̃̃O}

O estado de Roraima está situado no extremo norte do Brasil, apresentando uma cobertura vegetacional envolvendo ecossistemas florestais e não florestais. As florestas amazônicas cobrem cerca de $80 \%$ da sua superfície, principalmente ao sudeste e ao sul do estado (Barbosa et al. 2003; Sette-Silva 1997). Nestas regiões estão também as principais unidades de conservação federais, como os
Parques Nacionais do Viruá e a Floresta Nacional do Anauá. Apesar da presença destas unidades de conservação na região, o sul do estado é considerado uma das áreas vegetacionais mais devastadas em Roraima. Estas degradações são basicamente devidas às atividades de madeireiras, crescimento desordenado da agropecuária e a crescente migração de outros estados brasileiros (Barni et al. 2015). O município de São João da Baliza possui uma população de 6.769 habitantes 
(IBGE 2010) e está localizado em uma área florestal no sul do estado de Roraima, que também apresenta várias áreas de desmatamento.

Diante deste panorama, Flores (2014b) sugeriu que uma das formas para possibilitar a diminuição da velocidade de destruição das florestas no sul do Roraima envolve a conscientização da população local quanto a importância desta vegetação. Conscientização que pode ser iniciada pela difusão do conhecimento sobre a flora e a fauna ali existentes, por meio de atividades de divulgação científica envolvendo toda a comunidade. A divulgação científica envolve a tradução do conteúdo científico para o público leigo, a contextualização crítica e a discussão dos variados aspectos sobre essa informação, desde os positivos até os possíveis riscos, e os desdobramentos e as consequências sociais (Manso 2012).

Ações de divulgação científica e educacionais são extremamente importantes para as populações residentes em locais distantes dos centros de pesquisa científica, como já registrado por Flores (2014a) no interior do estado de Roraima. Desta forma, a realização de atividades como a Semana Nacional de Ciência e Tecnologia (SNCT) oferece a estas comunidades do interior uma oportunidade de interação entre pesquisadores, alunos e professores das escolas de ensino superior e básico.

Em 2013, o Ministério de Ciência, Tecnologia e Inovação (MCTI), por intermédio do Conselho Nacional de Desenvolvimento Científico e Tecnológico (CNPq) e da Secretaria de Ciência e Tecnologia para Inclusão Social (SECIS), lançou o edital "Difusão e Popularização da Ciência". Neste edital foram priorizadas propostas voltadas para a Semana Nacional de Ciência e Tecnologia, em atividades de divulgação científica e tecnológica e/ou pesquisas na área da comunicação pública da ciência, objetivando contribuir na popularização e difusão da ciência e para a melhoria da qualidade do ensino de ciências.

A proposta submetida a este edital pela equipe do Herbário do Museu Integrado de Roraima (IACTI-RR/MIRR), juntamente com pesquisadores da Universidade Estadual $\mathrm{e}$ Universidade Federal de Roraima (UERR e UFRR), foi contemplada. As ações propostas neste projeto pretenderam proporcionar uma melhor aprendizagem de conceitos científicos e a reflexão de novas maneiras de trabalhar estes conceitos em salas de aula e reforçar a importância da preservação das florestas amazônicas, especialmente por populações residentes no sul do estado. Assim, este minicurso sobre a diversidade da flora amazônica teve a finalidade contribuir de maneira significativa para a popularização e difusão da ciência e tecnologia, além de colaborar para a melhoria da qualidade do ensino de ciências, em especial à Botânica.

Este trabalho tem como objetivo relatar e discutir a experiência desta atividade de divulgação científica realizada em um município no sul do estado de Roraima, bem como discutir a importância destas atividades para comunidades distantes dos centros de pesquisa no estado e como estas ações podem auxiliar ao estímulo a aprender sobre as plantas.

\section{MATERIAL E MÉTODOS}

Este projeto envolveu a realização de um minicurso sobre a diversidade e conservação das plantas vasculares no sul do estado de Roraima. O público alvo do minicurso foram professores do ensino básico nas áreas de ciências e/ou biologia e estudantes do ensino superior, em especial dos cursos de licenciatura.

$\mathrm{Na}$ elaboração desta atividade foram seguidas as seguintes etapas: seleção dos conteúdos a serem tratados durante o minicurso, elaboração e produção do material impresso e vídeo que serviram como materiais complementares às aulas. Finalizando com a execução do minicurso durante a Semana Nacional de Ciência e Tecnologia em outubro de 2014.

Para o minicurso foram propostos como temas centrais a morfologia externa vegetativa e reprodutiva de plantas vasculares, a diversidade e a riqueza de famílias e de espécies botânicas e a utilização sustentável da flora utilizando como referencial as espécies encontradas nas áreas florestais no Sul do estado de Roraima. Além destes temas também foram apresentadas as questões ambientais atuais relacionadas à etnobotânica e conservação das espécies, que serviram de referencial em todos os temas.

Após a seleção dos conteúdos a serem tratados, foi feita a etapa de produção do 
material impresso e vídeo que serviram como material de apoio/didático ao curso. Para tanto, foi realizada uma excursão de campo, concentrada principalmente nas áreas florestais do Sul de Roraima, para a captação de fotos para a elaboração do material impresso e vídeo.

Para a produção do material impresso foram confeccionados livretos com informações científicas onde predominaram elementos visuais sobre os temas selecionados em forma de capítulos, a saber: 1.A Floresta Amazônica e a divulgação científica; 2.Como são descobertas novas espécies de plantas?; 3.Quem são as plantas vasculares?;4. Glossário ilustrado das principais estruturas das plantas vasculares; 5.As unidades de Conservação e a preservação da diversidade biológica; 6.As plantas, os saberes e a sustentabilidade. Os textos foram elaborados com uma linguagem acessível para o público alvo do minicurso, bem como para a comunidade em geral. Também foi produzido um vídeo educativo "As florestas no sul de Roraima" com duração de aproximadamente 10 minutos. $\mathrm{O}$ vídeo foi produzido utilizando os recursos do programa Movie Maker disponível em sistema operacional Windows. O vídeo abordou os aspectos de conservação da vegetação amazônica e a sua flora (principais espécies florestais e sua importância para a alimentação, econômica e ambiental), destacando a importância das unidades de conservação em áreas florestais em Roraima e as espécies ameaçadas de extinção. Este vídeo foi distribuído para os participantes durante a realização do curso, juntamente com o material impresso.

Ao final do minicurso foi aplicado um questionário no qual os participantes puderam avaliar a atividade. Para isso, foram elaboradas as seguintes perguntas:

1. Como você interpreta a importância educativa da atividade de campo realizada na Serra da Baliza?

2. Quais foram suas impressões sobre as atividades desenvolvidas durante este minicurso?

3. Como estas atividades poderão influenciar sua prática docente?

4. Quais foram os pontos positivos e negativos deste minicurso?
5. Quais são as suas sugestões para o aprimoramento das atividades desenvolvidas neste minicurso?

\section{RESULTADOS E DISCUSSÃO}

A divulgação do minicurso foi realizada no mês de setembro por meio de visitas a escolas para fornecer mais informações sobre o mesmo para os professores de ciências e biologia nos municípios de São João da Baliza, São Luís do Anauá e Caroebe. Nesta ocasião, também foram distribuídos os formulários de inscrição nas escolas para facilitar a divulgação do evento.

Durante a SNCT, no dia comemorativo ao professor, foi realizado no auditório da Universidade Estadual de Roraima (UERR) o lançamento do livreto "Ensinando Botânica nas florestas do Sul do estado de Roraima" publicado pela UERR Edições (Figura 1). Este livro fez parte do material que foi distribuído durante o minicurso em São João da Baliza.

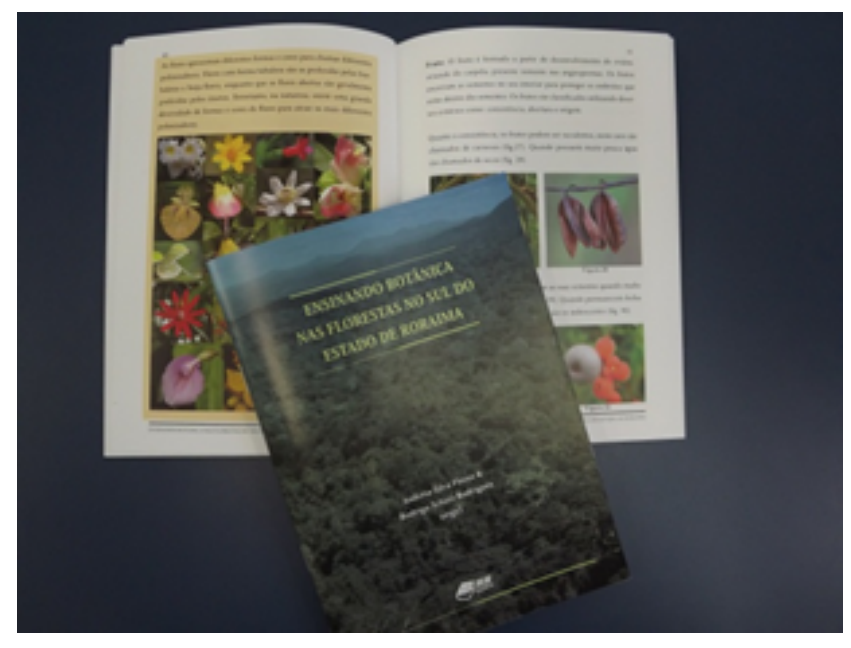

Figura 1. Livro publicado pela UERR Edições "Ensinando Botânica nas florestas do sul do estado de Roraima".

No lançamento estavam presentes professores de ensino básico e professores do ensino superior do estado, além de estudantes de graduação de diversos cursos de licenciatura. Neste evento, a coordenadora do projeto pode apresentar as atividades do minicurso, a importância da produção de materiais de divulgação científica com referenciais regionais para o ensino e também a necessidade de atividades de extensão em municípios do interior do estado. A coordenadora aproveitou também para estender 
o convite aos demais colegas pesquisadores para a produção de materiais de divulgação científica nas demais áreas do conhecimento científico.

Em três dias foi desenvolvido o minicurso no município de São João da Baliza. No primeiro dia os ministrantes do minicurso realizaram uma saída de reconhecimento da área natural da Serra da Baliza e coleta de partes de plantas para a atividade a ser desenvolvida no dia seguinte. No segundo dia foram realizadas aulas teórico/práticas sobre a diversidade morfológica das espécies pertencentes às principais famílias encontradas nas florestas amazônicas e aspectos sobre conservação, importância ambiental e uso sustentável desta flora (Figura 2).

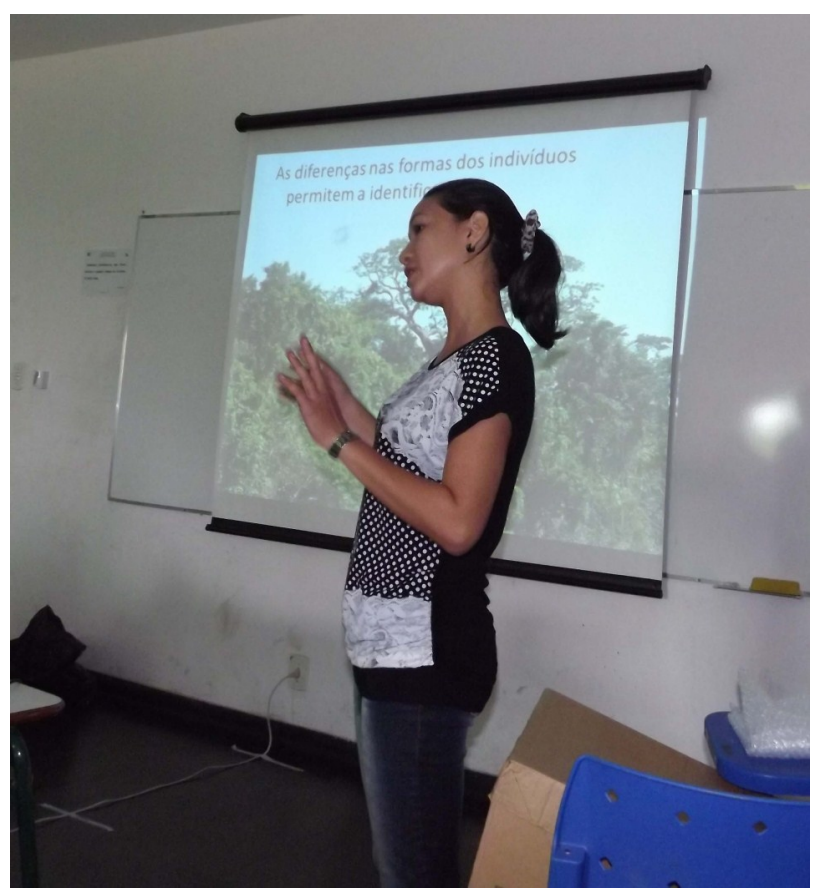

Figura 2. Aula teórico-prática desenvolvida durante o projeto "Conhecendo a diversidade das plantas vasculares da Floresta Amazônica" em São João da Baliza, Roraima.

No terceiro dia, foi realizada uma saída de campo com os participantes na Serra da Baliza para o reconhecimento das principais espécies e/ou famílias botânicas em seu habitat natural bem como a discussão sobre o estado de conservação da flora na região e sobre a importância das saídas de campo para o estímulo ao ensino de botânica (Figura 3). Ao final do terceiro dia foi feito o encerramento das atividades, onde os participantes produziram um documento sobre a experiência vivida no curso e seus principais resultados para sua capacitação profissional.

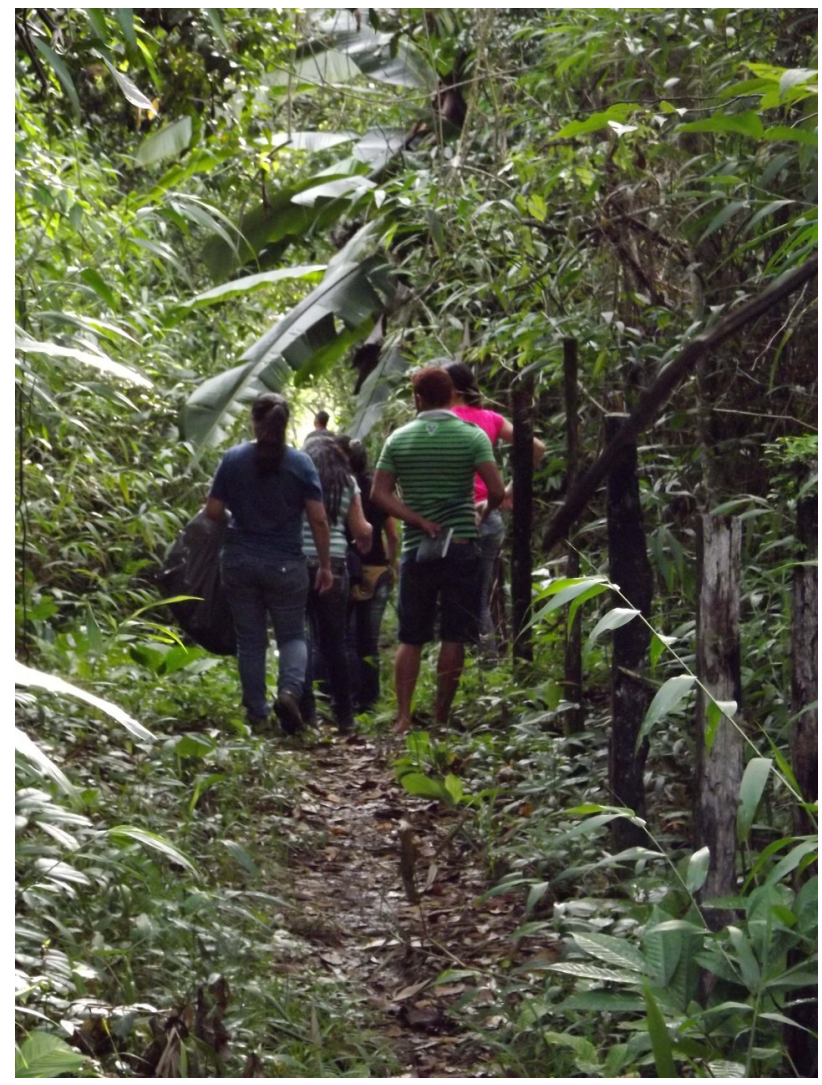

Figura 3. Aula de campo na Serra da Baliza durante o projeto "Conhecendo a diversidade das plantas vasculares da Floresta Amazônica" em São João da Baliza, Roraima.

O minicurso foi realizado com a presença de professores de ciências e de graduandos do curso de engenharia florestal. Essa interação se mostrou muito interessante, pois houve uma troca de experiências e de informações diferenciadas entre os cursistas. Os graduandos auxiliaram principalmente durante a saída de campo, onde auxiliaram os professores quanto as suas dúvidas sobre a utilização e manejo de algumas espécies madeireiras enquanto que os professores mencionaram as principais percepções que seus alunos tinham a respeito das espécies de plantas e sobre o ambiente.

$\mathrm{O}$ documento produzido ao final do curso foi realizado a partir de um breve questionário entregue ao final do segundo dia para a avaliação da atividade.

As respostas não variaram muito entre os participantes professores e os graduandos, exceto na questão 3, na qual os estudantes optaram por não responder. Os participantes relataram que a importância educativa da atividade de campo foi importante em dois 
aspectos básicos: conhecer a diversidade de formas e plantas em seu ambiente natural, enfatizando a importância da preservação destes locais e; o aspecto educativo onde foi levantada a importância da fixação e esclarecimentos de conceitos botânicos em uma atividade prática em locais externos à sala de aula.

As principais impressões sobre as atividades desenvolvidas durante o minicurso foram relacionadas à atividade prática e a distribuição dos livretos com o filme. Todos os participantes mencionaram a ótima qualidade dos livros que abordaram aspectos pouco discutidos em sala de aula (mesmo na graduação). Os professores mencionaram que os materiais auxiliarão muito durante sua prática docente, mas relataram também a dificuldade da realização de atividades de campo devido a falta de veículos nas escolas e falta de tempo.

Dentre os pontos positivos do minicurso foram citadas: conhecer a variação entre espécies e sua diversidade; conhecer as principais técnicas de coleta e herborização de plantas vasculares; local e percurso escolhido para a atividade de campo (próximo a sede da cidade), bem como as ferramentas utilizadas para visualização e coleta; material didático de ótima qualidade; organização do minicurso e da atividade prática; temas técnicos explicados de forma clara. Dentre os pontos negativos: pouca carga horária; alguns temas foram mais voltados ao ensino de ciências (alunos de graduação da engenharia florestal); pouca informação sobre cuidados no campo (proteção contra insetos, alergias, proteção contra insolação).

Dentre as sugestões para aprimoramento do minicurso foram: aumentar a carga horária do curso; realização de mais cursos no município; realização de minicurso voltado para a engenharia florestal. Destes, o aumento de carga horária foi o mais citado.

A botânica é considerada por muitos professores uma das mais difíceis áreas da biologia a ser trabalhada nas salas de aula no ensino básico e superior, principalmente por envolver terminologia técnica que é muitas vezes distante do cotidiano dos alunos (Kinoshita et al. 2006; Silva 2013). Além deste obstáculo, ainda há o desafio em reconhecer as plantas como algo além de componentes de paisagismos, mas como importantes seres vivos com papel de extrema importância na biosfera e sua diversidade (Wandersee \& Schussler 2001). Pensando nisto, e pela experiência gerada por ações de divulgação já realizadas anteriormente, verificou-se a necessidade de ampliar as atividades diferenciadas voltadas principalmente para $\mathrm{o}$ ensino na área de botânica. Dentre estas atividades, as saídas de campo oferecem um grande potencial de investigação e descoberta, pois permitem observar os seres vivos em seu ambiente e suas inter-relações na natureza. Na região amazônica podem ser utilizados vários locais para $\mathrm{o}$ desenvolvimento dos conceitos relacionados às Ciências Naturais, em especial a Botânica como áreas verdes, lagos e igarapés, entre outros (Queiroz et al. 2011).

Em geral, os minicursos referentes à botânica ministrados em Roraima visam o estímulo à pesquisa científica, sendo estes basicamente dedicados à identificação de famílias botânicas em áreas naturais. Desta forma, este minicurso proporcionou ao públicoalvo diferentes concepções sobre a temática de conservação e diversidade da flora Amazônica de modo que estes assuntos possam ser trabalhados em sala de aula.

Esta proposta inicialmente teve a intenção de atender a população, em especial educadores e futuros professores, residentes no sul do estado de Roraima. Os professores das escolas no interior do estado apresentam uma dificuldade de trabalhar as ciências utilizando referenciais regionais, devido à ausência de textos e outros materiais de apoio educacional com uma linguagem mais acessível e de fácil compreensão (Flores 2014a).

Tendo-se em vista que o público-alvo da proposta é composto por professores da rede básica de ensino e de graduandos em licenciatura residentes no município de São João da Baliza e municípios próximos, acredita -se na atuação destes como multiplicadores do saber trabalhado durante o curso, mesmo os graduandos do curso de engenharia florestal que futuramente podem atuar em redes públicas de ensino. Neste sentido, os participantes poderão são capazes de levar esse conhecimento aos seus alunos e aprimorá-lo com sua prática cotidiana, utilizando como material de apoio o livreto e vídeo em sala de aula. A abrangência da proposta aumentará na medida em que os participantes do curso serão estimulados a repetir a experiência em suas escolas, atuando como disseminadores de informação. 
Espera-se que esta proposta resulte em uma conscientização da conservação e uso sustentável dos recursos vegetais nos professores e licenciandos e que estes atuem em suas escolas como agentes de difusão para os seus alunos presentes e futuros. Em termos de melhoria específica do ensino de botânica, espera-se que o curso atualize e capacite os professores de ciências e biologia, incentivando -os a adoção de modalidades de ensino utilizando os recursos naturais próximos de suas escolas. Além disso, a produção de material didático produzido para este curso poderá auxiliar os professores como material de apoio em suas aulas. Também se espera estimular a formação de novos pesquisadores na área de Botânica e na área de ensino de ciências.

\section{AGRADECIMENTOS}

A autora agradece a equipe do projeto "Conhecendo a diversidade das plantas vasculares da Floresta Amazônica"; aos participantes do minicurso realizado em São João da Baliza; ao Conselho Nacional de Desenvolvimento Científico e Tecnológico $(\mathrm{CNPq})$ e da Secretaria de Ciência e Tecnologia para Inclusão Social (SECIS), pelo financiamento do projeto (processo 405753/2013-6).

\section{REFERÊNCIAS BIBLIOGRÁFICAS}

Barbosa, R. I.; Xaud, M. R.; Silva, G. F. N. \& Cattâneo, A. C. 2003. Forest Fires in Roraima, Brazilian Amazonia. International Forest Fire News 28: 5156.

Barni, P.E. et al. 2015. Avaliação socioambiental na cidade de Rorainópolis, região sul de Roraima. Boletim do Museu Integrado de Roraima 9 (2): 2333.

Flores, A.S. 2014a. "Os segredos das flores dos lavrados": Relato de uma ação educativa na área de Botânica no extremo norte do Brasil. Boletim do Museu Integrado de Roraima 8 (1): 10-18.

Flores, A.S. 2014b. A Floresta Amazônica e a divulgação científica. In: Ensinando botânica nas florestas no sul do Estado de Roraima. Flores, A.S. \& Rodrigues, R.S. (org.). Boa Vista: UERR Edições, p: 13-17.

IBGE. Instituto Brasileiro de Geografia e Estatística. 2010. São João da Baliza. Disponível em http:// cidades.ibge.gov.br/painel/painel.php?

lang=\&codmun=140050. Acesso em: 13 de maio de 2016.

Kinoshita, L. S.; Torres, R. B.; Tamashiro, J. Y.; ForniMartins, E. R. (orgs). 2006. A botânica no ensino básico: relatos de uma experiência transformadora. $1^{\mathrm{a}}$ ed. Editora Rima, São Carlos, 162p.

Manso, B.L.C. 2012. Divulgação científica: o desafio de popularizá-la na própria ciência. Revista do Encontro de Divulgação de Ciência e Cultura 1: 47-57.

Queiroz, R., Teixeira, H.B., Veloso, A.S., Terán, A.F. \& Queiroz, A.G. 2011. A caracterização dos espaços não formais de educação científica para o ensino de ciências. Revista Amazônica de Ensino de Ciências (Areté) 4 (7):12-23.

Sette-Silva, E.L. 1997. A vegetação de Roraima. In: Barbosa R.I., Ferreira E.J.G. \& Castellón E.G. (eds). Homem ambiente e ecologia no Estado de Roraima. Manaus, INPA. p. 401-415.

Silva, J. R. S. 2013. Concepções dos professores de botânica sobre ensino e formação de professores, Tese (Doutorado) - Instituto de Biociências da Universidade de São Paulo.

Wandersee, J.H.; Schussler, E. 2001. Toward a theory of plant blindness. Plant Science Bulletin 47(1): 2-9. 